\title{
Negócio à moda antiga: tropas de comércio em Diamantina nos meados do século $\mathrm{XX}$
}

\section{Older forms of business: troops of trade in Diamantina in the middle of the 20th Century}

\author{
Marcos Antônio LOPES* \\ Marcos Lobato MARTINS**
}

\begin{abstract}
Resumo: Este artigo analisa uma variedade de aspectos relacionados à atuação das tropas de comércio nas Minas Gerais ao longo dos séculos XIX e XX. Agente central da economia mineira por largo tempo, ressalta-se o conjunto de narrativas dos viajantes estrangeiros sobre o fenômeno do tropeirismo oitocentista, o que ajuda a compreender certos sentidos sociais e culturais implicados no objeto em tela. A partir das memórias de antigos almocreves do Alto Jequitinhonha, procura-se demonstrar, também a notável longevidade alcançada pelas tropas de comércio na região de Diamantina, fenômeno que persistiu até os anos 1950.
\end{abstract}

Palavras-chave: Tropas e tropeiros.Ttransportes arcaicos no interior do Brasil. Viajantes do século XIX. Memórias de ex-tropeiros.

Abstract: The authors analyze a variety of issues relative to the activities of trading caravans in the State of Minas Gerais over the $19^{\text {th }}$ and $20^{\text {th }}$ centuries. These caravans were a main attribute of this State's economy for a long time. A collection of foreign travelers' stories about the phenomenon of the nineteenth century drover is also highlighted, which helps in understanding certain social and cultural meanings concerning it. Through the memoirs of the old muleskinners from Alto Jequitinhonha, the authors also seek to demonstrate their remarkable longevity in Diamantina, a phenomenon that persisted until the 1950s.

\footnotetext{
* Marcos Antônio Lopes, doutor em História Econômica pela Universidade de São Paulo, é professor na Universidade Estadual de Londrina. Rodovia Celso Garcia Cid - PR 445, KM 380 — Campus Universitário. Caixa postal 6001. CEP 86051-980. Londrina/PR. E-mail: malopes@uel.br.

** Marcos Lobato Martins, doutor em História Econômica pela Universidade de São Paulo, é professor na Universidade Federal de Alfenas. Rua Gabriel Monteiro da Silva, 700, Alfenas/MG, CEP 37130-000. E-mail: lobatohistoria@hotmail.com.
} 
Keywords: Muleskinners and drovers, archaic transportation in Brazil's countryside, travelers from the $19^{\text {th }}$ century, Ex-drovers' memoirs

Um dos desafios a que a economia mineira teve de responder foi o relacionado ao escoamento da produção de víveres e demais artigos. Desafio portentoso devido à topografia acidentada das Minas Gerais e das distâncias que a separam do litoral brasileiro. Desde o século XVIII e até bem adiantado o século XX, a solução encontrada por vastas regiões de Minas Gerais para este desafio foi a tropa burriqueira, quase o único elemento utilizado para o transporte de cargas e pessoas. Carros de bois tiveram seus préstimos no transporte de curta distância entre fazendas e arraiais ou vilas, nas regiões de topografia mais suave. Os barcos foram muito utilizados em rios como o São Francisco, Velhas, Jequitinhonha, Grande e Sapucaí. (MATTA MACHADO, 2002).

O papel destacado das tropas na vida regional no século XIX pode ser aquilatado pelas observações de John Luccock, relativas a São João Del Rei no período joanino. Como se sabe, esta vila prosperou rapidamente como centro fornecedor de mantimentos para o Rio de Janeiro, cujo crescimento era impulsionado pela chegada da Corte portuguesa. Marcada, até então, por uma relação comercial sempre negativa com o Rio de Janeiro, a vila mineira viu alterar-se sensivelmente tal situação. Segundo o relato de Luccock,

Desde, porém, a vinda da Corte, o valor dos produtos aumentou tanto que não só a dívida se liquidou como a região se tornou credora da capital [...] E esse comércio — o de São João Del Rey — é mantido por meio de quatro tropas regulares, cada qual com cerca de 50 burros, que perfazem geralmente oito jornadas por ano. (LUCCOCK, 1942, p. 312).

$\mathrm{Na}$ verdade, todas as localidades mineiras tiveram seu abastecimento estreitamente vinculado ao vai e vem das tropas. Os antigos “caminhos de tropa” possibilitaram a integração do território, criaram ou modificaram cidades. No Alto Jequitinhonha, Turmalina cresceu como ponto de pouso das caravanas que transitavam entre Minas Novas e o Tijuco (atual Diamantina). No Sul de Minas, a localidade de Fama teve movimento enquanto por ela passaram tropas originárias de áreas drenadas pelos rios Grande e Sapucaí, demandando a estrada que ligava São João Del Rei ao Rio de Janeiro. O trânsito das tropas marcou a fisionomia de muitas localidades com o rancho, o largo e as hospedarias.

As tropas de comércio não podem ser confundidas com a animalhada condutora dos produtos da lavoura para os mercados municipais. Esse conjunto de animais de carga não passava de cargueiros cavalares que não possuíam “a regra” da tropa, nem empregavam muares como peças 
centrais de seu negócio. (FRANCO, 1942). Assim é que o termo "tropa” deve designar apenas o comércio de transportes estruturado e caracterizado por técnicas e controles muito particulares. Segundo Caio Prado Júnior,

[...] o transporte terrestre na colônia não se achava entregue aos azares das circunstâncias e confiado à improvisação; é um negócio perfeitamente organizado, sobretudo nas capitanias do centro-sul. [...] Os trajetos são fixados com datas certas de chegada e partida bem como tabelas estabelecidas de fretes. (PRADO JÚNIOR, 1996, p. 261-62).

Como se vê, o tropeirismo foi uma empresa pensada para atuar com eficiência, gerar confiança e satisfação da clientela e, essência de sua razão de ser, produzir lucro. Com efeito, as tropas de muares foram os principais “drenadores” das riquezas para o litoral e vice-versa, o que, sem dúvida, resultava em inegável prestígio político e social para os praticantes desse difícil e oneroso ofício. (DORNAS FILHO, 1959). Por isso, “[...] o tropeiro e seus auxiliares representavam aristocracia”. (CALÓGERAS, 1936, p.582).

De fato, para que um indivíduo pudesse tornar-se tropeiro, algumas condições elementares deveriam ser preenchidas: antes de tudo, era necessário capital inicial de monta para a aquisição dos animais, além de alguma instrução e habilidade com finanças, sem a qual era impossível ao chefe dirigir o comércio, deter eficaz controle sobre os pagamentos bem como aquilatar os lucros de seus empreendimentos. (PEIXOTO, 1951). No quadro da economia escravista da primeira metade do século XIX, a montagem de uma tropa custava polpudas economias em dinheiro, importando em alguns contos de réis, haja vista a necessidade de adquirir cargueiros (em geral comprados na feira de Sorocaba, na província paulista) e escravos. Os gastos diários com uma tropa também implicavam em dispêndios, como a remuneração dos tocadores, a alimentação destes, dos “escravos tropeiros” e dos animais, a renovação periódica da arreata, além de outros serviços que tanto mais se avolumavam quanto maior era a tropa. Desse modo, tropeiros eram encontrados mais frequentemente entre as famílias rurais de escol. Em geral, eles eram os filhos dos fazendeiros mais abastados. (PEIXOTO, 1951).

Vale lembrar que, na Zona da Mata mineira de meados do século XIX, muitos pioneiros cafelistas mantiveram em suas propriedades tropas de muares, empregadas para escoar a sua produção e a de vizinhos, rumo ao Rio de Janeiro. Tratava-se de estratégia que, por um lado, barateava os custos de transporte da safra e, por outro lado, possibilitava diversificar os negócios da família proprietária e reforçar sua ascendência sobre médios e pequenos agricultores da região. (OLIVEIRA, 1999). 
O tropeirismo constituiu uma porta de entrada para a projeção social e política. Grossas fortunas foram amealhadas no negócio das tropas. Comprando nas vilas e cidades do litoral os gêneros, as fazendas e os utensílios de variada espécie, o tropeiro os transportava para as regiões interiores a penosos custos. No entanto, ganhava nessa difícil atividade altas porcentagens. Com o passar do tempo esse agente prosperava. Alguns enriqueciam de maneira a não deixar dúvidas quanto ao bom sucesso de seus empreendimentos. Incrementando o vulto de seus negócios, com o passar do tempo, determinados tropeiros dirigiram à distância os fornecimentos de mercadorias, deixando a penosa execução pessoal do ofício a profissionais contratados para este fim. Enriquecidos, alguns tropeiros chegaram a fazer carreira política, atingindo destacadas alturas. (ZAMELLA, s.d.).

Talvez o caso mais famoso de homem que angariou fortuna e prestígio a partir da lida com tropas seja o de Antônio Silva Prado, o Barão de Iguape, que viveu de 1788 a 1875. (PETRONE, 1976). No início do século XIX, Antônio Prado saiu de São Paulo conduzindo pequena tropa rumo a Goiás, em seguida estabeleceu-se em Caitité, na Bahia, onde montou um “armarinho”. Fez serviços de tropa e de cobrança de dívidas de comerciantes paulistas, entre 1810 e 1816 . No ano seguinte, de volta a São Paulo, Antônio Prado amealhara capital suficiente para se lançar em grandes negócios: ampliou sua fortuna imensamente tornando-se contratador de impostos (em Sorocaba), negociante de gado e mulas e comerciante de açúcar.

Outro exemplo, embora menos espetacular, é dado pelo Coronel Manoel César Pereira da Silva, proprietário da “intendência do meio” e minerador cuja fortuna, na Diamantina da virada do século XIX para o XX, originou-se com as tropas e o comércio de aguardente. Intendência era o nome dado pelos moradores de Diamantina aos grandes ranchos de tropas existentes na cidade, e que concentravam os negócios ligados a compra e venda de mantimentos até os anos 1880. Um dos maiores chefes da política local, o Coronel conservou seu filho, João César de Oliveira - pai do pequeno "Nonô”, o futuro Presidente da República Juscelino Kubitschek de Oliveira -, na condição de tropeiro que circulava pelo Norte de Minas.

\section{Narrativas dos viajantes estrangeiros}

Para uma análise do que representaram as tropas de comércio nos quadros da economia mineira do século XIX, afora a documentação relativa aos apontamentos dos Registros, os relatos dos viajantes que visitaram o Brasil no período também são fontes de grande interesse. O importante Registro de Matias Barbosa, por exemplo, foi retratado por John Mawe em termos muito esclarecedores: 
Este registro é um vasto edifício oblongo, com duas portas em cada extremidade, pelas quais todos os viajantes com seus animais são obrigados a passar. [...] O edifício possui, no interior, quartos para os oficiais, ranchos para os soldados, celas para prisão de pessoas suspeitas e cocheiras para os animais. Há no pátio grande número de estacas, nas quais se amarram os burros, enquanto são carregados e descarregados. (MAWE, 1944, p. 151).

Acerca dos Registros é preciso dizer que, por volta dos inícios do século XVIII, surgiram algumas dessas primeiras “alfândegas” coloniais. Os Registros de fronteira, verdadeiras barreiras fiscais internas implantadas em pontos estratégicos, proibiam a passagem dos que não possuíam guia especial fornecida pelas autoridades competentes. Nos Registros cobrava-se o ingresso de tudo, obrigando os tropeiros a pagarem os "direitos de entrada” sobre os bens que traziam. (SALGADO, 1985). Ao naturalista George Gardner causou espanto a voracidade tributária dos registros:

[...] a umas 10 léguas e meia do Chapéu de Uva [em direção a Ouro Preto] passamos pela primeira barreira que encontrei em uma estrada pública do Brasil. Todos os animais, carregados ou não, pagam aqui 30 réis por légua, soma que é também cobrada de pedestres. A distância daqui à barreira é de 10 léguas e paga-se aqui pela distância a percorrer até a próxima barreira, que era então o ponto terminal da parte completa da estrada. (GARDNER, 1942, p. 431).

Frequentemente, os viajantes proporcionam dados e observações perspicazes e minuciosas acerca das condições de trabalho e de vida diária dos tropeiros. De fato, uma boa imagem do cotidiano das tropas pode ser percebida nas descrições dos viajantes que circularam pelo interior do Brasil, especialmente Burton, Gardner, Luccock, Maximiliano, Mawe, Spix, von Martius, e SaintHilaire. Em seus livros sente-se o fervilhar dos caminhos mineiros e o modo de vida dos tropeiros em muitas de suas particularidades. Com efeito, os viajantes conheceram as tropas de perto, e participaram delas em alguma medida; quase sempre, arrancharam com tropeiros e, não raro, tiveram um tropeiro como guia seguro de suas expedições.

Além de pormenores de natureza econômica - especificação de mercadorias em seus respectivos volumes e valores - outros motivos referentes às tropas parecem ter ocupado muito da atenção dos viajantes: a caracterização dos trechos percorridos; a descrição pormenorizada do número de animais; e a descrição, no detalhe do detalhe, do tipo físico e dos elementos típicos da vestimenta dos tropeiros. Em obras de viajantes do século XIX as tropas de comércio são caracterizadas como o mais autêntico símbolo da economia do sertão mineiro, o agente por excelência da circulação e da vida econômica das Minas Gerais. 
Em algumas edições das obras dos viajantes encontram-se ilustrações feitas por artistas que os acompanhavam em suas embaixadas científicas por todos os quadrantes dessas terras. É por esse meio que se pode formar uma boa visão dos ranchos de tropas, das cargas e arreamentos, da feitura da comida sobre as trempes de ferro batido, dos tropeiros em descanso após um dia de marcha. Enfim, tais obras costumam proporcionar uma caracterização fidedigna do dia a dia das tropas pelas difíceis trilhas de Minas. Percepção clara das dificuldades do tropeirismo aparece no relato de John Mawe, mineralogista inglês que visitou o interior do Brasil a convite da casa real portuguesa durante os anos de 1807 a 1818. Seu trabalho indicou alguns dos contínuos transtornos enfrentados pelos tropeiros. Segundo ele,

[...] as viagens são fatigantes e dispendiosas: é necessário comprar milho todos os dias para os burros e, apesar dos cuidados de que os cercam, muitos morrem, outros se estropiam, tornando-se inaptos para o serviço. A carga é dividida em duas partes iguais e suspensa por correias de couro cru a uma albarde, de estrutura particular. O peso médio de carga é a de nove arrobas, que equivalem a cerca de 300 libras; e o custo do transporte, por carga, do Rio de Janeiro a Minas Novas (localidade situada ao norte do Tijuco-Diamantina, a caminho de Araçuaí), é de seis a sete libras esterlinas; ao Tejuco, de cinco libras; e a Vila Rica, de três libras. (MAWE, 1944, p. 230).

O testemunho de Mawe permite vislumbrar o sofrimento da gente da tropa no percurso de caminhos dilatados, em viagens que duravam dezenas de dias. Relatos da década de 1860 informam que a viagem de Diamantina ao Rio de Janeiro durava entre 15 e 20 dias, no mínimo. De Diamantina para Minas Novas, a marcha era de cerca de 10 dias. E, de Diamantina ao Serro, duas cidades vizinhas, a viagem durava 3 dias. (DUARTE, 1917). Estimativas de tempos de viagens de tropas setecentistas e oitocentistas aparecem em outros autores. (GOULART, 1959).

Fatores naturais e as condições dos trechos percorridos faziam com que jamais fosse possível realizar uma viagem completa sem que se tivesse de mexer na carga sucessivas vezes, retirando-a completamente do lombo das mulas para, na sequência, recolocá-las sobre os animais. Nos momentos de repouso e nas travessias dos rios, quando o volume de água estava na altura das cargas, tornava-se absolutamente necessário o descarregamento completo numa margem e o recarregamento dos volumes na outra. No caso de algum desarranjo ou desajuste da carga sobre o lombo das mulas, era preciso a recomposição imediata do conjunto, sob pena de "pisar" o animal. Portanto, deve-se afastar qualquer concepção edulcorada da profissão de tropeiro que lhe confira traços de romantismo, aventureirismo e vida livre em contato com a natureza.

A propósito, H. D. Beaumont, Secretário da Legação Britânica no Rio de Janeiro, ao visitar Diamantina no ano de 1899, observou que, “segundo o hábito do Brasil”, os tocadores de tropa 
trajavam roupas velhas e gastas, completamente sujos de tanto carregarem peso. Conforme as palavras do diplomata: “Os condutores são sempre negros ou mulatos em trajes leves, que caminham descalços e trazem muitas vezes bizarros chapéus de couro da Bahia [...]. Nunca exigem cama. Eles dormem em uma guarda com a sela de seus animais como travesseiros”. ( $O$ MUNICÍPIO, ano IV, n. 230). Perfil bastante distinto da imagem popular do tropeiro gaúcho, representado na iconografia tradicional com botas de couro, chapéu largo e coberto por grossas mantas. Ainda sobre os incômodos, dificuldades e rudes condições de percurso, Luccock discursa em termos que não deixam dúvidas acerca da face mais rude das lides nas tropas:

O proprietário dalguma fazenda constrói isso a que chamam um 'rancho', que no geral, não passa de um telheiro comprido e largo, sustentado por esteios toscos sem lavrar, de cerca de 20 pés de altura; seu fim é proporcionar abrigo contra o sol e a chuva, mas geralmente não tem parede nenhuma e frequentemente, também, nem o chão lá dentro é aplainado [...]. É sob esses galpões que aqueles que viajam com tropas geralmente tomam pouso à noite [...]. (LUCCOCK, 1942, p. 249).

Outro viajante que enfatizou o calvário das viagens pelo interior das Minas Gerais oitocentistas foi o naturalista J. E. Pohl. Ele queixou-se dos pousos, mas também dos atrasos e perdas nas jornadas decorrentes do comportamento dos animais cargueiros:

Insuportável é a fumaça que, mormente no tempo das chuvas, quando a lenha está inteiramente molhada, enche todo o rancho e se mistura com as exalações dos couros de boi usados para cobrir a bagagem, afetando penosamente os órgãos da vista e do olfato. Quando pretendíamos partir, na manhã [...] repetiu-se a desagradável cena da véspera; mal puseram as cargas sobre os animais, eles impetuosamente as lançaram abaixo, quebrando as cangalhas e destroçando completamente dois dos meus baús. (POHL, 1951, p. 139).

Sem dúvida, o rotineiro "voluntarismo” dos próprios animais era um dos percalços mais irritantes para o viajante, o que faz recordar o Brás Cubas de Machado de Assis, numa das "aventuras” que lhe sucedeu, quando de seus estudos em Coimbra. Encarapitado no lombo de uma mula, já de retorno ao Brasil, viu-se atirado ao chão sem atinar ao certo com o motivo daquela reação. Restou-lhe agradecer os préstimos do zeloso almocreve, guia atento da expedição rumo a Lisboa, que conseguiu desembaraçá-lo em tempo hábil do estribo a que ficara preso. (MACHADO DE ASSIS, s.d.).

Richard Burton - que por aqui esteve no fim da década de 1860 - referiu-se às tropas que transitavam no interior mineiro com certo bom humor e algum detalhismo. Segundo ele em seu Viagens aos Planaltos do Brasil, "os navios do deserto luxuriante da América do Sul”, carregados de sal e de quinquilharias que constituíam a principal importação, traziam para o litoral café e 
algodão. Quanto às estruturas de apoio oferecidas àqueles que se embrenhavam pelas antigas estradas do Brasil no século XIX, Burton identificou uma espécie de evolução, discernível nos caminhos mais movimentados.

A “primeira fase”, afirma, “é a de 'pouso', mero terreno para acampar, em que o proprietário consente que os tropeiros dêem água aos seus burros ou os amarrem aos mourões [...]. A segunda fase é o 'rancho', que corresponde ao bungalow de viajantes, faltando, porém, o leito, cadeira e mesa [...]. A terceira fase é a 'venda', progresso decidido, mas não integralmente respeitável [...]; é a 'pulperia' das colônias hispano-americanas, o empório da aldeia inglesa combinado com a mercearia e a hospedaria. Vende tudo, desde cabeças de alho e livro de missa até genebra, aguardente, doces e velas [...]. A quarta fase é a 'estalagem' ou 'hospedaria', onde nos hospedamos em Mariana [...]. (BURTON, 1941, p. 177179).

Praticamente nada havia mudado nas condições dos pousos na última década do século XIX. Na região de Diamantina, os pousos “[...] constavam quase sempre do rancho e de uma pequena casa ao lado, onde o proprietário residia com a família, com um minúsculo armazém, que fornecia aos passageiros carne seca, feijão, farinha, cachaça e milho para os animais”. (ARNO, 1949, p. 116). Já no início do século XX, as maiores casas comerciais de Diamantina começaram a controlar pousos de tropeiros, oferecendo melhores acomodações para os viajantes e visando a vantagens na aquisição das cargas. Cita-se apenas um exemplo: em Riacho das Varas (atual Conselheiro Mata), na estrada de Diamantina para Curralinho (atual Corinto), a firma Antônio Eulálio \& Cia. possuía rancho de tropas, pasto e moinho que, no ano de 1916, data da liquidação da empresa, foi vendido a Dona Júlia Carolina da Silva pela quantia de 500 mil réis (Escritura de venda, de 7 de janeiro de 1916. Livro de Notas n. 32, Cartório do $1^{0}$ Ofício, Maço 496. Biblioteca Antônio Torres. IPHANDiamantina).

Acerca dos modos de viajar e do cotidiano das tropas, George Gardner - que visitou o Brasil entre os anos 1836 a 1841, para realizar estudos de botânica - anotou observações interessantes no livro Viagens no Brasil, principalmente nas Províncias do Norte e nos Distritos do Ouro e do Diamante: "O modo de viajar nas províncias do sul, achamo-lo bem diverso daquele a que nos acostumáramos no norte. Raramente ou nunca se usam cavalos e só se faz uma caminhada por dia, a qual, conforme a natureza da estrada, se estende de três a quatro léguas”. “As tropas”, segue o relato de Gardner, "às vezes de mais de 150 mulas, são bem organizadas: as que não são conduzidas pelo próprio dono são entregues a um arrieiro ou almocreve que, montado a cavalo, segue atrás da tropa”. (GARDNER, 1942, p.393-394). De acordo com os ex-tropeiros do Jequitinhonha, a idade de uma besta definia a carga a ser transportada. Assim, um animal de até três anos não deveria carregar 
mais de oito arrobas em marchas regulares. Somente as mulas já mais afeitas aos percursos eram carregadas com um volume que variava de nove a doze arrobas.

John Luccock - cuja permanência no Brasil situou-se entre os anos 1808 a 1818 - apresenta um quadro pormenorizado das atividades comerciais entre o litoral e o interior brasileiro. A narrativa de Luccock inicia-se por sua passagem pelo Porto da Estrela, vilarejo no litoral fluminense que funcionava como o grande empório para o comércio mineiro com o litoral. Essa vila portuária, verdadeiro empório, era o ponto final da estrada que descia de Minas Gerais para o Rio de Janeiro. Praticamente tudo quanto ia de Minas para o Rio de Janeiro tinha seu ponto terminal na passagem das tropas por Porto Estrela:

[...] nesse ponto [relata Luccock], fica a aldeia de Porto da Estrela, interessante pela sua grande atividade, embora não possua muitas casas, algumas delas são insolitamente boas. [...] o que mais importa é que ali existem dois canais com armazéns apropriados, donde se embarcam para a capital muitos dos produtos do interior. De vez que as estradas principais do país começam ou terminam nessa localidade, ali se desembarcam e carregam em lombo de burro todas as mercadorias que se destinam à região norte da capitania do Rio de Janeiro, a Minas Gerais, a Mato Grosso e Goiás, lugares esses dos quais se encontram de 1500 a 2000 milhas de distância. (LUCCOCK, 1942, p. 226).

Daí em diante o autor se dedica às minúcias do embarque e aos respectivos cuidados com as mercadorias:

\begin{abstract}
Os [objetos] que se destinam ao interior [...] são postos em fardos de cerca de 4 pés de comprido, três de largo e dois de fundo e embrulhados em tela encerada, a fim de protegê-los da ação do tempo. Arrumam-nos juntando criteriosamente artigos pesados e artigos volumosos, de maneira a que o fardo todo pese mais ou menos 70 libras. Os chapéus e gêneros que não podem ser enfardados muito apertadamente, tal os sujeitos a quebrarem-se ou estragarem-se pela pressão, são postos dentro de engradados e cobertos igualmente de tela encerada. (LUCCOCK, 1942, p. 245).
\end{abstract}

Além dos viajantes acima citados, a tropas foram também retratadas por outros visitantes europeus como, por exemplo, Auguste de Saint-Hilaire e Spix e Martius, conforme os títulos citados nas referências bibliográficas deste artigo.

\title{
O futuro do passado no Norte de Minas Gerais
}

Curiosamente, em plena era da industrialização do Brasil, as tropas de comércio continuaram ativas em diversas partes do país. No Norte de Minas Gerais, particularmente nos anos 1920-50, elas ainda atuavam interligando uma série de municípios. No decurso da primeira metade 
do século passado, afluíam diariamente a Diamantina tropas vindas de todos os quadrantes regionais. Na cidade, era muito freqüentes a passagem de tropeiros de Capelinha, do Serro, Rio Vermelho, Serra Azul de Minas, Santo Antônio do Itambé e localidades vizinhas. As tropas da região de Araçuaí e Minas Novas eram bastante regulares. Menos comuns, mas relativamente presentes, eram as tropas do Norte de Minas: chegavam de Engenheiro Dolabela, de Bocaiúva e até de Montes Claros.

O movimento intenso das tropas no Mercado Municipal de Diamantina, nas primeiras décadas do século $\mathrm{XX}$, refletiu significativamente na composição das rendas auferidas pela Municipalidade. Os números, bastante elucidativos, encontram-se alinhavados no quadro abaixo, extraídos de A Estrela Polar, segundo relatório apresentado ao Dr. Raimundo Gonçalves da Silva, Juiz de Direito da Comarca de Diamantina, pelo Presidente da Câmara e Agente Executivo Municipal Juscelino Demerval da Fonseca. Belo Horizonte:

Rendas relativas ao Mercado Municipal

Diamantina - 1915 a 1937

\begin{tabular}{|l|r|r|r|}
\hline \multicolumn{1}{|c|}{ Rendas municipais } & \multicolumn{1}{c|}{1915} & \multicolumn{1}{c|}{1929} & \multicolumn{1}{c|}{1937} \\
\hline Renda total do município & $72: 370 \$ 000$ & $140: 230 \$ 000$ & $407: 343 \$ 000$ \\
\hline Aferição de pesos e medidas & $200 \$ 00$ & $254 \$ 000$ & - \\
\hline Renda do Mercado & $13: 000 \$ 000$ & $26: 953 \$ 000$ & $108: 847 \$ 100$ \\
\hline Aluguel de cômodos do Mercado & $600 \$ 000$ & $1: 750 \$ 000$ & - \\
\hline Total da renda do Mercado & $13: 800 \$ 000$ & $28: 957 \$ 000$ & $108: 847 \$ 100$ \\
\hline \% sobre a renda municipal & $19 \%$ & $21 \%$ & $27 \%$ \\
\hline
\end{tabular}

Esta sobrevivência das tropas não se constituiu em simples anacronismo, em apenas um fragmento do passado já sem sentido econômico, existindo apenas por força de fatores psicológicos como a teimosia ou, quem sabe, a nostalgia dos tempos heróicos das velhas tropas. Pelo contrário, a plena atividade das caravanas de muares no Vale do Jequitinhonha durante as primeiras cinco décadas do século XX deve ser percebida como uma persistência histórica, plena de sentido econômico, como uma continuidade regionalizada do antigo sistema colonial de circulação de bens e valores. De fato, o Vale do Jequitinhonha nos anos de 1920-50 ainda era um encravamento geográfico, ou seja, um “espaço-tempo” marcado por considerável isolamento, comunicando-se apenas parcialmente com as regiões mais dinâmicas da economia mineira como, por exemplo, a própria capital.

A título de ilustração, apenas em anos muitíssimos recentes é que as estradas que interligam pequenas localidades como Santo Antônio do Itambé e Serra Azul de Minas a centros maiores 
como o Serro estão recebendo pavimentação. Muitos trechos - verdadeiros atoleiros em épocas de chuva - ainda não foram concluídos e, no percurso de Serra Azul de Minas a Rio Vermelho, a cobertura asfáltica sequer foi iniciada, sem se saber ao certo se será algum dia. Apenas muito lentamente é que esses rincões perdidos de um "Brasil profundo” foram se desligando das estruturas arcaicas do passado.

Esta condição peculiar da região de Diamantina, de relativo isolamento geográfico, pode ser explicada, grosso modo, por dois fatores. O primeiro é o abandono da região por sucessivos governos mineiros a partir dos anos 1920, na medida em que se formou consenso político de que a concentração de esforços e recursos na industrialização da Zona Metalúrgica (área central de Minas Gerais) seria a melhor estratégia para o desenvolvimento do Estado. Com isso, Diamantina e o Norte de Minas receberam parcos investimentos, especialmente no que se refere aos modernos sistemas de transporte. (sobre as políticas governamentais mineiras de desenvolvimento e seus efeitos, ver Dulci, 1999). O segundo fator é a própria dinâmica da economia regional, cujos ritmos e trocas eram comandados pela mineração de diamante (e, em menor escala, de ouro). As grandes fortunas derivavam dos negócios com diamantes, muito mais do que da agricultura de abastecimento. Ora, as gemas preciosas, que continuaram a ser o principal produto de exportação regional, não dependiam de boas estradas e meios modernos de transporte nem para serem extraídas nas lavras, nem para serem comercializadas no Rio de Janeiro. Por isso, para os maiores homens de negócio de Diamantina, bastava a estrada de ferro, que atingira a cidade no ano de 1914.

Nesse quadro, portanto, as tropas de comércio conservaram algo de seu antigo sentido econômico e social. No enovelado das estreitas picadas, no difícil acesso das chapadas que tão bem caracterizam a topografia das municipalidades surgidas ao redor do antigo arraial do Tijuco, o tropeirismo continuou a ser fator de articulação econômica do intercâmbio comercial entre Diamantina e as comunidades sob sua influência.

Com o advento da ferrovia, as tropas de muares ainda se mantiveram como os únicos elos de um comércio, agora de médio alcance, cobrindo trechos em torno de 10 léguas. Da mesma forma que havia ocorrido em outras regiões do Brasil, à medida que as linhas férreas se estendiam, as tropas redesenharam suas trilhas, encurtando-as consideravelmente. A expansão ferroviária não implicou numa diminuição automática do fluxo de tropas. Os trilhos foram uma concorrência apenas parcial e sem grande poder de eliminação das funções das tropas. Disso dá mostras o anúncio de 1906, publicado em jornal diamantinense: “Anúncio. Josefino de Araújo Silva e seus irmãos José, Luiz e Miguel encarregam-se do transporte de mercadorias, em carros ou em tropa, da Estação de Curralinho para Diamantina ou vice-versa, cobrando o carreto muito barato. Riacho das Varas”. (JORNAL A IDEA NOVA, p. 3). No mesmo sentido apontam as recordações do Sr. Oscar 
Lopes - grande comerciante que começou a vida recebendo comissões de tropeiros no Mercado Municipal de Diamantina -, antes da chegada da ferrovia as tropas iam buscar seus produtos em Curvelo; com o avanço dos trilhos em direção à Bahia, passaram a ir para Corinto.

Quando em Diamantina, as caravanas de mulas rodeavam o Mercado Municipal para serem descarregadas, o Sr. Mário Nicolau Pereira - ex-tropeiro que até o início dos anos 1990 trabalhou com reprodução de muares para venda - informa-nos que, nos meses da seca, quando o comércio se intensificava, era frequente deparar-se com numerosos lotes de animais aguardando em ruas e becos próximos ao Mercado por sua vez de descarregar:

Tinha época de não caber mais... o tropeiro não tinha como dormir. Tinha de dormir pro lado de fora ou então na Palha (descendo a ladeira que leva na direção do Caminho dos Escravos). Duzentos e quarenta burros já contei lá no Mercado. Quando as tropas enchiam o Mercado, a saída era ir pra Palha. Naquela época, além de rancho pros tropeiros lá tinha bom pasto. O dono do rancho cobrava quatrocentos réis por cabeça (Informação verbal) ${ }^{1}$.

Segundo o Sr. José de Sá, octogenário em 1990, e um dos testemunhos mais lúcidos do movimento de tropas em sua cidade,

[...] os tropeiros traziam gêneros comestíveis, transportados em bruacas de couro para o Mercado. Lá, a mercadoria era vendida aos comerciantes por atacado, pessoalmente ou por atravessadores que ganhavam porcentagem. Os tropeiros voltavam levando encomendas como objetos de ferragem, louças, perfumes, fazendas e, alguns credenciados, até mala de correio (Informação verbal)².

Convém ressaltar, conforme as lembranças de Walter Baracho, que as transações entre tropeiros e comerciantes diamantinenses muitas vezes se faziam pelo sistema de crédito. Isto significa que havia tropeiros que entregavam mercadorias "em consignação, para que os comerciantes as vendessem; [...] em contrapartida, o comerciante vendia de tudo para o tropeiro, que acertava quando de sua volta a Diamantina”. (Depoimento publicado na Voz de Diamantina, p. 7). Esta era a prática típica do comércio colonial que persistiu na região até a primeira metade do século XX.

O Mercado de Diamantina atendia às necessidades peculiares às tropas. Debaixo do grande telheiro de terra batida todos os acessórios da tropa encontravam o seu lugar natural: desde a raspadeira dos animais, passando pelo embornal do tropeiro, pelos apetrechos de cozinha, até as peças do complicado arreamento. Os animais eram amarrados nos esteios, descarregados cuidadosamente, e seus pêlos raspados - alguns recebiam um banho de água com sal no lombo, para curar ferimentos provocados pela fricção da cangalha ou das cargas. À tardinha, os animais seguiam 
para os pastos, na periferia da cidade. As bruacas eram depositadas em pilhas no chão do Mercado cada lote da tropa tomava o seu canto, formando como que pequenos quartos dentro do edifício. Nesses “compartimentos” dormiam os tocadores e donos de pequenas tropas. Diante deles, armavam-se as trempes de cozinha, nas quais eram preparados o café e as refeições dos tropeiros (almoço por volta das dez horas; jantar lá pelas dezesseis horas). Feitas as obrigações dos tocadores, eles passeavam pela cidade e bebiam cachaça nas vendas e bares.

Os tropeiros proprietários das maiores tropas tinham estadas melhores, alojavam-se em hotéis ou pensões de Diamantina, jogavam baralho e bebiam com os amigos nos reservados dos armazéns ou dos cabarés do Beco do Mota, na época, a mais destacada zona de meretrício da cidade. A descrição do cotidiano dos tropeiros no Mercado de Diamantina está baseada no depoimento de Augusto Domingos Ribeiro, ex-tropeiro da localidade de São Gonçalo do Rio das Pedras, situada entre Serro e Diamantina.

O Mercado Municipal de Diamantina jamais conseguiu cumprir a contento a finalidade principal que justificou sua criação, no ano de 1890: garantir a emancipação do povo da "tutela dos monopolizadores”. O Decreto de 3 de julho de 1895, que determinou o funcionamento do Mercado, estabeleceu que os gêneros alimentícios seriam vendidos livremente pelo tropeiro, repartidamente entre consumidores e comerciantes, e que só haveria a venda por atacado depois de findo o prazo de 24 horas, contadas do momento da exposição dos gêneros. O Decreto citado foi publicado no jornal O Município, ano I, n. 35, 6 de julho de 1895. Biblioteca Antônio Torres. A letra da lei, que privilegiava a garantia de abastecimento a preços módicos aos consumidores locais de menor renda, foi recorrentemente desrespeitada pelos próprios fiscais e diretores do Mercado, sob a pressão dos comissários das maiores casas comerciais de Diamantina. A esse respeito, serão citamos apenas dois indícios deste fato. O primeiro é a reclamação estampada na edição de 14 de fevereiro de 1905, do jornal O Itambé:

Continua suspenso o varejo de gêneros alimentícios no Mercado Público, medida esta que causa grande dano ao povo. [...] Ficar ao arbítrio do diretor designar a quantidade que deve ser varejada, está bem longe de autorizá-lo a suprimi-lo de vez, pois outra exatamente foi a intenção do legislador. Mais de uma pessoa tem vindo ao nosso escritório reclamar contra este ato arbitrário. (O ITAMBÉ, 1905)

O segundo é o depoimento de um ex-almocreve, o Sr. Mário Pereira, que atuou no Mercado de Diamantina nos anos 1940: “O tropeiro chegava com a mercadoria e os Lopes já tinham um comprador esperando no Mercado. Se o preço tava bom a gente vendia: quando não tava a gente esperava uns dias. Se não melhorasse, a gente ia pra outros lugares ou então tomava o prejuízo”. Ao mencionar os Lopes, o depoente se refere à firma Lopes \& Irmãos, uma das maiores casas 
comerciais de Diamantina que, nessa época, disputava o controle do abastecimento local com a firma Motta e Companhia.

Os depoimentos de ex-tropeiros e comerciantes revelam que os plantéis de muares eram bastante heterogêneos quanto ao número. Havia indivíduos que tropeiravam com número superior a cinco lotes, e elementos que não possuíam além de três a cinco animais. À tropa incompleta, isto é, ao lote com número inferior a dez animais dava-se o nome de puxada. Os depoimentos não confirmam uma participação efetiva de mulheres lidando com tropas completas e regulares. Fala-se apenas em algumas bruaqueiras que tocavam puxadas ao longo de trechos mais curtos. Entretanto, há relato quanto a certa Senhorinha de Bruno, tropeira do Rio Vermelho que, nos inícios do século $\mathrm{XX}$, realizava um comércio regular e, de quebra, também se encarregava de conduzir donzelas das melhores famílias para o Nossa Senhora das Dores. Esse antigo internato diamantinense, tornado bastante conhecido por seu passadiço suspenso a unir as dependências dos dois lados da íngreme ladeira, foi por longo tempo referência nacional na educação de moças das melhores famílias. O trabalho infantil também foi largamente utilizado. Quase todas as tropas possuíam um menino ocupando as atribuições de cozinheiro.

Na primeira metade do século passado, a tropa típica no Vale do Jequitinhonha era composta por lote de dez cargueiros, mais um cavalo (ou égua) “madrinheiro”. Este, montado pelo dono da tropa, andava bem adornado e solto no meio da caravana. Na frente da fileira de animais, aparecia o "burro de guia”, munido de peitoral com seis cincerros e “pisteira” de pura prata, adornando a parte frontal da cabeça. Este animal, que carregava menos peso que os demais, recebia a função de marcar a viagem. Bem treinado, ele sabia os caminhos que a tropa percorria e impedia que os outros cargueiros passassem à frente nas encruzilhadas e paradas. O "burro de coice”, geralmente o mais carregado de todos os animais da tropa, seguia no fim da fila. Sua tarefa era a de empurrar os animais do meio que parassem de marchar. Fechando a caravana, aparecia uma pequena mula carregada com os apetrechos da cozinha e os mantimentos dos tropeiros.

Nessas pequenas tropas da região, a divisão de trabalho era simples. O dono - ou seu auxiliar de confiança, chamado de "arrieiro" - cuidava da compra e venda de mercadorias. Os “tocadores”, geralmente dois, no máximo três, cuidavam dos animais, arriavam, carregavam e descarregavam os cargueiros ao longo de todo o percurso. O cozinheiro da tropa, uma criança, preparava o café e as refeições nos pousos, além de ajudar os tocadores a carregar e descarregar os animais.

No entorno de Diamantina, a marcha diária dos cargueiros era de cerca de três léguas (21 km), percorrida nas primeiras horas do dia. Por volta das 14 horas, no máximo, a tropa detinha a marcha e pousava. No dia seguinte, retomava a marcha. As informações sobre a composição e a 
marcha das tropas da região de Diamantina baseiam-se nos depoimentos dos ex-almocreves José Maria Lopes (Córrego do Mel), Augusto Domingos Ribeiro, Nestor Araújo e Joaquim dos Santos Júnior (todos de São Gonçalo do Rio das Pedras).

Associado aos aspectos de composição e organização da tropa, um traço do tropeirismo que desperta a curiosidade do observador é a chamada "regra" da tropa. Os tropeiros da região de Diamantina se jactavam de terem sido exímios conhecedores da “regra”, sinal de prestígio e experiência. O fato é que havia entre as tropas uma subdivisão por categorias hierárquicas. As poucas tropas de primeira linha, que possuíam, no mínimo, cinco lotes de cargueiros, distinguiamse pela riqueza dos adornos dos animais, notadamente do “madrinheiro”. A “regra” também impunha procedimentos padronizados à marcha dos animais e à conduta dos tropeiros, uma espécie de “ética” secular, observada com esmero.

Como recorda um ex-tropeiro do Jequitinhonha, o Sr. Mário Pereira: “A tropa tinha de saber como ficava no rancho... no mercado. Se uma tropa estava chegando no rancho, os tropeiros que já estavam lá tinham que ajudar a descarregar o primeiro lote e servir café para os outros”. As tropas de comércio tenderam a desaparecer bruscamente a partir da introdução de caminhões em nossa região ali pelos fins dos anos 1940. Fato curioso, a tropa coexistiu com o automóvel durante certo tempo. Um depoimento, do Sr. Mário Pereira, parece esclarecedor a este respeito:

Fui tropeiro desde 1940. Tinha a idade de 23 anos. Mexia com cargueiro desde menino. Parei com a tropa porque passou a dar pouco. Os carros tomaram conta. O caminhão passava pela tropa várias vezes na estrada... passava carregado de feijão... tornava a passar de volta... passava de novo. O lote de burros carregava só mil e duzentos quilos e o caminhão, além de carregar mais, andava mais depressa. Em 1962, eu ainda tinha mais de um lote de burros... levei para puxar lenha do retiro para as casas e as padarias de Diamantina (PEREIRA, 1990)

Para concluir com as palavras de João Dornas Filho, nos dias de hoje talvez não mais façamos nem mesmo uma remota idéia do que foi uma "tropa", no sentido que assumiu no passado e por tão longo tempo. Numerosos lotes de muares cobrindo léguas intermináveis, para transportar drogas e produtos da terra ao litoral, trazendo de lá tudo que fosse necessário à vida, articulando núcleos urbanos de diversas dimensões no interior do país. Com efeito, as tropas foram os primeiros meios de transporte e comércio que o Brasil possuiu, e seu maior elemento econômico e social da colonização e fixação do homem. A longa presença das tropas de comércio em numerosas regiões brasileiras não decorreu apenas das dificuldades impostas pela geografia ao transporte de mercadorias e pessoas, mas principalmente do fato de que os saberes tradicionais dos tropeiros 
possibilitaram o desenvolvimento de técnicas de transporte eficientes o bastante para perdurarem por muito tempo.

\section{Notas}

${ }^{1}$ A informação foi dada pelo Sr. Mário Nicolau Pereira em entrevista oral em 1990.

${ }^{2}$ A informação foi dada pelo Sr. José de Sá em entrevista oral em 1990.

Recebido em 20/10/2010

Aprovado em 09/05/2011

\section{Referências}

ARNO, C. Memórias de um estudante. Rio de Janeiro: Gráfica Olímpica, 1949.

BURTON, R. Viagens aos planaltos do Brasil. Rio de Janeiro: Editora Nacional, (Coleção Brasiliana, v. 197). 1941.

CALÓGERAS, P. Transportes Archaicos. In: Estudos Históricos e Políticos. (Coleção Brasiliana, v. 74). 1927.

DORNAS FILHO, J. Aspectos da Economia Colonial. Belo Horizonte: Itatiaia, 1959.

DUARTE, J. R. Recordações mineiras. Rio de Janeiro: Tipografia Leuzinger, 1917.

GOULART, J. A. Meios e instrumentos de transporte no interior do Brasil. Rio de Janeiro: MEC, 1959.

DULCI, O. S. Política e recuperação econômica em Minas Gerais. Belo Horizonte: Editora UFMG, 1999.

FRANCO, A. A. M. Páginas do Passado Brasileiro: Tropas e Tropeiros. In: Cultura Política. Revista Mensal de Estudos Brasileiros. Rio de Janeiro: 1942, Ano II, n. 12.

GARDNER, G. Viagens no Brasil principalmente nas províncias do Norte e nos Distritos do Ouro e do Diamante durante os anos de 1836-1840. (Coleção Brasiliana, v. 223).

LUCCOCK, J. Notas sobre o Rio de Janeiro e partes meridionais do Brasil - 1808/1818. São Paulo: Livraria Martins, 1942.

MACHADO DE ASSIS. O almocreve. In: — Memórias póstumas de Brás Cubas. Rio de Janeiro: Editora Prazolivro, s.d. (Coleção Romances de Machado de Assis).

MATTA MACHADO, F. Navegação do Rio São Francisco. Rio de Janeiro: Topbooks, 2002.

MAWE, J. Viagens ao interior do Brasil principalmente aos distritos de Ouro e do Diamante. Rio de Janeiro. Zélio Valverde, 1944.

OLIVEIRA, Mônica Ribeiro de. Negócios de famílias: mercado, terra e poder na formação da cafeicultura mineira - 1780-1870. Niterói: ICHF/UFF, 1999. (Tese de doutorado). 
PEIXOTO, L. Principais caminhos fluminenses para as Minas Gerais. Rio de Janeiro: Imprensa do Estado do Rio de Janeiro, 1951.

PETRONE, M. T. S. O Barão do Iguape, um Empresário da Época da Independência. São Paulo: Companhia Editora Nacional, 1976.

POHL, J. Viagem no interior do Brasil - 1817/1821. Rio de Janeiro. Instituto Nacional do Livro, 1951.

PRADO JÚNIOR, C. Formação do Brasil Contemporâneo. São Paulo: Brasiliense, 1996. (Primeira edição: 1942).

SAINT-HILAIRE, A. Segunda viagem do Rio de Janeiro à Minas Gerais e a São Paulo. (Coleção Brasiliana, v. 5).

SAINT-HILAIRE, A. Viagem às nascentes do Rio São Francisco. Belo Horizonte: Itatiaia, 1975.

SAINT-HILAIRE, A. Viagem pelas províncias do Rio de Janeiro e Minas Gerais. Belo Horizonte: Itatiaia, 1975.

SAINT-HILAIRE, A. Viagem pelo distrito dos diamantes e do litoral do Brasil. Belo Horizonte: Itatiaia, 1974.

SALGADO, G. (Org.). Administração Fazendária. In. Fiscais e Meirinhos. Rio de Janeiro: Publicação do Arquivo Nacional, 1985.

SPIX \& MARTIUS. Viagem pelo Brasil. Rio de Janeiro: Imprensa Nacional, 1938.

ZAMELLA, M. O abastecimento da capitania de Minas Gerais no século XVIII. São Paulo: USP, s.d.

\section{Periódicos de época}

A ESTRELA POLAR, ano XIII, n. 2, 10 de janeiro de 1915. Imprensa Oficial, 1931. Secretaria das Finanças do Estado de Minas Gerais. Exportação do Estado e Arrecadação das Exatorias em 1937. Belo Horizonte: Imprensa Oficial, 1939.

A IDEA NOVA, ano I, n. 12, 4 de julho de 1906. Biblioteca Antônio Torres. IPHAN-Diamantina.

O ITAMBÉ, 14 de fevereiro de 1905. Biblioteca Antônio Torres. IPHAN-Diamantina.

O MUNICÍPIO, ano I, n. 35, 6 de julho de 1895. Biblioteca Antônio Torres. IPHAN-Diamantina.

O MUNICÍPIO, ano IV, n. 230, 16 de junho de 1900. Biblioteca Antônio Torres. IPHAN-

Diamantina.

VOZ DE DIAMANTINA, ano II, n. 77, $1^{\circ}$ de fevereiro de 2003. Biblioteca Antônio Torres. IPHAN-Diamantina. 